\title{
Pelatihan Manajemen Kelompok Masyarakat bagi Petani Ikan Nila di Desa Paya Udang Kecamatan Seruwai Kabupaten Aceh Tamiang
}

\section{Zidni Ilman Navia*1, Sandri Maulizar², Ramaidani' ${ }^{3}$, Milfa Aini' ${ }^{4}$, Sri Rahayuni5, Sindi Mahyuda6, Ridho Maulana Andika ${ }^{7}$}

\author{
1.2.3.4.5.6.7Program Studi Biologi, Fakultas Teknik, Universitas Samudra, Indonesia \\ *e-mail: navia1529@gmail.com ${ }^{1}$
}

\begin{abstract}
Abstrak
Paya Udang merupakan salah satu desa yang terletak di kecamatan Seruway kabupaten Aceh Tamiang, Propinsi Aceh. Karena kurangnya pemahaman terkait manajemen kelompok masyarakat dalam penglolaan budidaya ikan air tawar di desa Paya Udang maka perlu dilakukan pelatihan menajemen kelompok. Tujuan dari kegiatan pelatiahan ini adalah untuk membantu masyarakat desa Paya Udang dalam membentuk kelompok budidaya ikan air tawar di desa Paya Udang dan untuk meningkatkan kesadaran masyarakat di desa Paya Udang pentingnya membentuk usaha dengan melibatkan kelompok. Kegiatan ini dilakukan di desa Paya Udang, Kecamtan Seruway, Kabupaten Aceh Tamiang dengan melibatkan 20 orang peserta. Metode yang digunakan berupa pendekatan Participatory Rural Appraisal (PRA) dan Community development. Hasil dalam kegiatan pelatihan ini adalah terbentuknya kelompok budidaya ikan nila di desa Paya Udang Kecamatan Seruwai Kabupaten Aceh Tamiang yang dikoordinir langsung oleh ketua BUMK desa.
\end{abstract}

Kata kunci: Ikan Air Tawar, Kelompok Budidaya Ikan, Manajemen Kelompok, Paya Udang

\begin{abstract}
Paya Udang is a village located in Seruway sub-district, Aceh Tamiang district, Aceh Province. Due to the lack of understanding regarding community group management in managing freshwater fish farming in Paya Udang village, it is necessary to conduct group management training. The purpose of this training activity is to assist the Paya Udang village community in forming a freshwater fish farming group in Paya Udang village and to increase public awareness in Paya Udang village the importance of forming a business by involving groups. This activity was carried out in Paya Udang village, Seruway sub-district, Aceh Tamiang district, involving 20 participants. The methods used are Participatory Rural Appraisal (PRA), Participatory Technology Development, and Community development approaches. The result of this training was the formation of a tilapia cultivation group in the village of Paya Udang, Seruwai District, Aceh Tamiang Regency, which was coordinated directly by the head of the village BUMK.
\end{abstract}

Keywords: Fish Farming Group, Freshwater Fish, Group Management, Paya Udang

\section{PENDAHULUAN}

Praktik menajemen berkaitan dengan strategi, alat dan teknik menajerial untuk meningkatkan kualitas, proses hasil, dan kompetisi (Chakraborty, 2019). Pelatihan menajemen dilakukan melalui pelatihan, dimana ada proses berbagi pengalaman belajar yang menciptakan perubahan yang relatif permanen pada individu untuk meningkatkan kemampuan mereka melakukan pekerjaan dan menjalankan usaha (Thassanabanjong, 2015; Alatas, 2018). Kelompok masyarakat yang dipandang strategis diberikan pelatihan dan pendampingan menajemen kelompok adalah sekelompok masyarakat yang memiliki potensi alam yang besar namun masih minim kemampuannya untuk mengelola hasil usahanya. Dalam hal ini adalah masyarakat di Desa Paya Udang Kecamatan Seruwai Kabupaten Aceh Tamiang. Di Desa Paya Udang juga terdapat BUMK (Badan Usaha Milik Kampung) merupkaan salah satu badan usaha yang dikelolah oleh kampung dimana dalam badan usaha tersebut memberikan modal kepada masyarakat untuk membuka usaha atau memperluas usaha yang dilakukan oleh suatu kelompok masyarakat yang bertujuan untuk mensejahterakan masyarakat yang ada di kampung tersebut (Wahyuni, 2020).

Desa Paya Udang terletak di Kecamatan Seruway dan berada di sekitar bantaran sungai Tamiang. Masyarakat di Desa Paya Udang memiliki kolam ikan air tawar yang berlimpah dan belum dikelola secara maksimal karena berbagai keterbatasan sehingga hasil usahanya masih 
terbilang minim. Dalam menjalankan usaha budidaya ikan air tawar ini masyarakat masih melakukannya secara individual. Namun, seiring perjalananya ditemukan berbagai permasalahan yang dihadapi oleh petani ikan nila tersebut, salah satunya belum terbentuknya kelompok tani budidaya ikan nila. Hal ini dikarenakan kurangnya pengetahuan masyarakat terkait pentingnya kelompok dan manajemen kelompok tersebut dalam upaya peningkatan usaha mereka. Sehingga saat ini masyarakat masih berjalan secara individu. Menurut Wicaksono (2020) mengatakan bahwa, dengan adanya manajemen kelompok yang baik akan mendukung manajemen usaha yang baik untuk menghasilkan pendapatan masyarakat.

Berdasarkan permasalahan yang dihadapi oleh masyarakat tersebut maka dari itu kami berinisiatif untuk memaksimalkan potensi yang dimiliki oleh Desa Paya Udang tersebut, langkah awalnya adalah memberikan pelatihan manajemen kelompok. Pelatihan ini diharapkan dapat menjadi langkah awal dalam perbaikan sistim kelompok masyarakat petani ikan nila dengan melibatkan anggota BUMK. Menejemen kelompok pada masyarakat di desa Paya Udang bertujuan agar dapat menambah wawasan, pengetahuan, dan keterampilan baru untuk menangkap peluang dan menghadapi persaingan melalui praktik menajemen. Manajemen kelompok penting dilakukan karena akan mempengaruhi budaya organisasi serta kinerja organisasi masyarakat (Macias-Jimines, 2019; Rahayu \& Magdalena, 2021). Harapannya dengan terbentuknkya kelompok tani tersebut dapat menjadi wadah bagi petani ikan nila di Desa Paya udang dalam mengelola budidaya ikan tersebut sehingga dapat mendukung program pemerintah desa. Pemerintah Desa Paya Udang telah melakukan upaya dalam perbaikan budidaya ikan air tawar tersebut, salah satunya dengan memasukkan program budidaya ikan nila sebagai produk unggulan daerah.

\section{METODE}

Metode yang digunakan dalam kegiatan PHP2D ini berupa pendekatan Participatory Rural Appraisal (PRA) yang menekankan keterlibatan masyarakat dalam keseluruhan kegiatan mulai dari perencanaan, pelaksanaan dan evaluasi program kegiatan dan Community development yaitu pendekatan yang melibatkan masyarakat secara langsung sebagai subyek dan obyek pelaksanaan kegiatan pengabdian kepada masyarakat. Data awal yang digunakan sebagai dasar pelaksanaan kegiatan diperoleh melalui wawancara untuk mendapatkan informasi secara langsung yang dapat menjelaskan dan menjawab permasalahan secara obyektif. Penggunaan data sekunder berupa studi kepustakaan dengan membaca literature-literatur yang berkaitan serta menunjang penulisan ini.

Tahapan kegiatan yang dilakukan yaitu koordinasi dengan kepala desa dan penanggungjawab BUMK, selanjutnya tim pelaksana menyampaikan rencana pelaksanaan kegiatan untuk kelompok sasaran. Tim pelaksana kegiatan menjelaskan secara detail rincian dan jadwal kegiatan kepada kepala desa, Ketua BUMK, serta masyarakat Desa Paya Udang dalam rangka sosialisasi kegiatan pada tanggal 12 September 2021. Kegiatan sosialisasi yang bertujuan memberikan informasi secara menyeluruh kepada pihak pihak yang terlibat dalam kegiatan ini dengan metode diskusi langsung. Tahapan berikutnya adalah pelatihan manajemen kelompok yang dilaksanakan pada tanggal 23 September 2021 dan diikuti oleh masyarakat desa Paya Udang sebanyak 20 orang. Selanjutnya tahapan pendampingan berupa diskusi langsung kepada kelompok masyarakat dan Ketua BUMK untuk tindaklanjut pembentukan kelompok tani Desa Paya Udang.

\section{HASIL DAN PEMBAHASAN}

Kegiatan pengabdian ini salah satu rangkaian dari kegiatan Program Holistik Pembinaan dan Pemberdayaan Desa (PHP2D) bagi masyarakat petani ikan nila di Desa Paya Udang. Dalam menjalankan kegiatan ini dilalui beberapa tahapan, mulai dari kegiatan sosialisasi pelatihan menajemen dilakukan pada tanggal 12 September 2021 bersama dengan Kepala Desa, ketua BUMK, dan anggota masyarakat petani ikan nila. Tahap sosialisasi ini kami melakukan penetapan 
jadwal kegiatan pelatihan menajemen kelompok petani ikan nila. Setelah dilakukan tahap penjadwalan kegiatan pelatihan menajemen kelompok barulah ditetapkan tanggal pelatihan menejamen kelompok yaitu tanggal 23 September 2021.

Kegiatan pelatihan manajemen kelompok diikuti oleh masyarakat petani ikan nila di desa Paya Udang sebanyak 20 orang. Metode pelaksanaan kegiatan yaitu dilakukan dengan metode Ceramah kemudian pemeteri tersebut menyampaikan atau menjelaskan mengenai menajemen kelompok pada masyarakat petani kolam ikan nila di desa Paya Udang.vPelaksanaan pelatihan menajemen kelompok pada masyarakat petani ikan Nila secara umum berjalan lancar sesuai dengan target yang ditetapkan oleh tim pelaksana (Tim PHP2D), indikator kesuksesan pelaksana dapat dilihat dari terbentuknya kelompok budidaya ikan air tawar di desa Paya Udang Kecamatan Seruway Kabupaten Aceh Tamiang yang dikoordinir langsung oleh BUMK desa (Gambar 1).
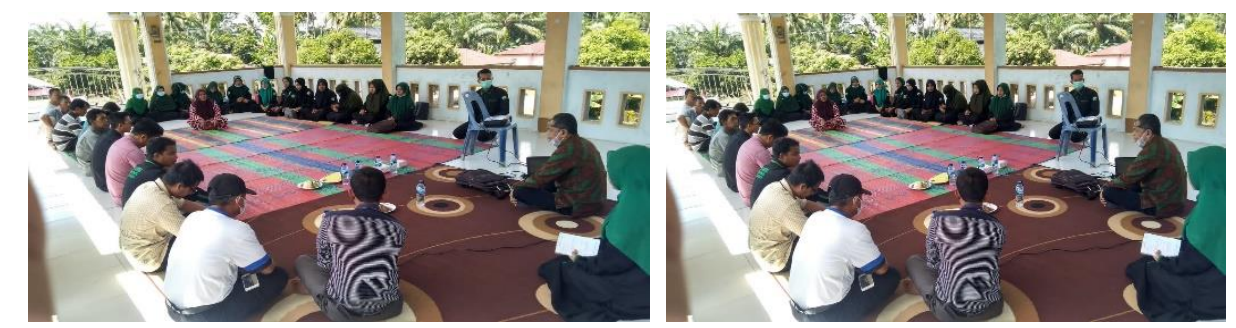

Gambar 1. Antusias Masyarakat di Desa Paya Udang Mengikuti Pelatihan Menajemen Kelompok

Materi kegitan pelatihan menajemen kelompok ini dipaparkan oleh bapak Zulkarnain Mora. SE., HRD, beliau merupakan salah satu dosen dari Fakultas Ekonomi Universitas Samudra. Dalam pemaparanya dari bapak Zulkarnain menyampaikan bahwa kelompok adalah kumpulan yang terdiri dari dua individu atau lebih yang saling berinteraksi dan saling bergantung, saling bergabung untuk mencapai tujuan tertentu. Pembentukan kelompok baru bertujuan agar terjadi peningkatan kapasitas kelembagaan yang mana ini sangat penting mengingat kelompok merupakan "jantung" dan "roh" suatu organisasi (Rudiono et al., 2021). Kemudian ciri-ciri utama terbentuknta kelompok adalah terdapat dorongan dari kelompok itu sendiri, terdapat interaksi yang berlainan, pembentukan dan penegasan struktur (organisasi), terjadinya penegasan dan peneguhan norma-norma pedoman tingkah laku. Adapun manfaat dari kelompok itu sendiri yaitu sebagai alat perjuangan bagi anggotanya, meningkatkan inovasi dan kreatifitas dalam pengambilan keputusan, dapat mengendalikan dan mendisplinkan anggotanya dibandingkan dengan mereka yang individualisme, sedangkan manfaat dari anggota kelompok adalah memiliki penghasilan, ada pekerja sampingan selain IRT dan memahami secara luas makna organisasi (Gambar 2).
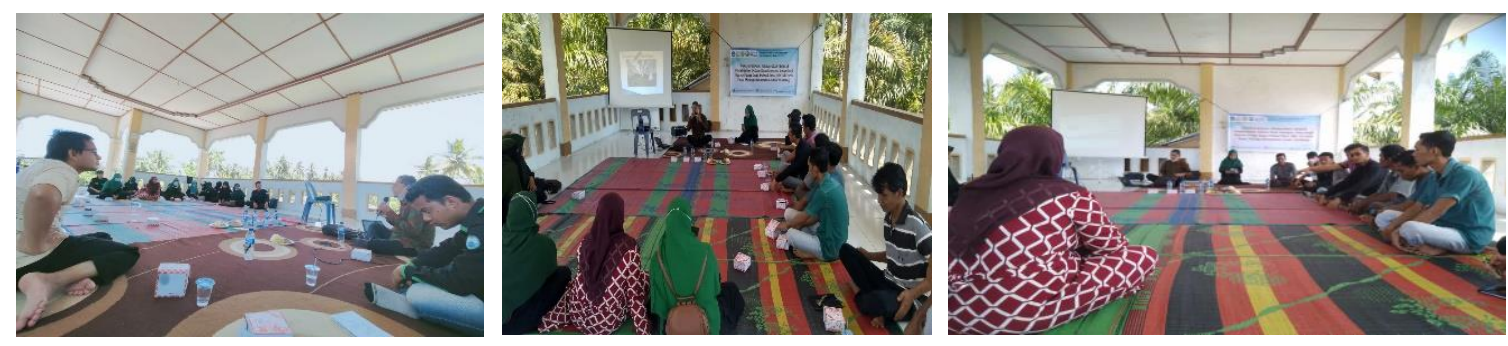

Gambar 2. Pemaparan Materi Pelatihan Menajemen Kelompok

Dalam pelatihan ini bapak Zulkarnain memaparkan bahwa tujuan dari menerapkan usaha dalam kelompok juga sudah di paparkan pada Undang-Undang Dasar Nomor 5 Tahun 1999. Dalam kelompok juga dibedakan dalam beberapa jenis yaitu kelompok kepentingan, kelompok informal, dan kelompok persahabatan, sehingga bapak Zulkarnain menyinpulkan bahwa "Berkerja Berkelompok itu lebih muda dilaksanakan dari pada bekerja secara individual" (Gambar 3). 

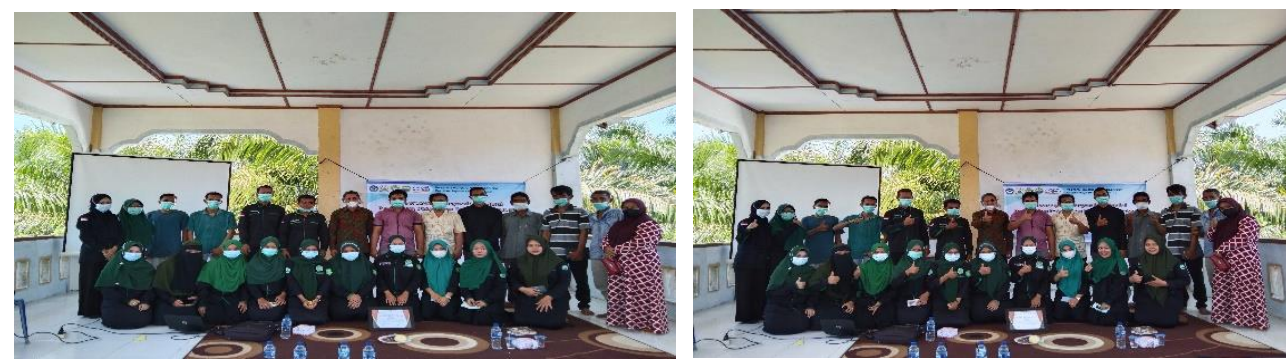

Gambar 3. Documentasi Kegiatan Dan Penyerahan Sertifikat Kepada Pemateri Pelatihan Menajemen Kelompok

Dalam kegiatan pelatihan menajemen kelompok, masyarakat sangat antusias mengikutinya dan dapat membuka wawasan mereka. Mereka berfikir bahwa dengan melakukan suatu usaha secara berkelompok sangat mengutungkan dan apabila mengalami kerugian dalam usaha tersebut maka akan ditanggung bersama oleh anggota kelompok.

Tindak lanjut dari kegiatan ini yaitu pendampingan dan monitoring terhadap kegiatan yang telah berjalan. Adapun hasil dari kegiatan pelatihan menajemen kelompok ini adalah telah terbentuknya kelompok budidaya ikan air tawar di desa Paya Udang Kecamatan Seruwai Kabupaten Aceh Tamiang yang dikoordinir langsung oleh ketua BUMK desa. Kelompok budidaya mereka di beri nama "Pemuda Jaya" dengan jumlah anggota kelompok yaitu 8 orang yang diketuai oleh Ramzan dan dengan adanya pelatihan menajemen kelompok ini sudah membantu mitra dalam mengelolah budidaya ikan air tawar di desa Paya Udang, Kecamatan Seruway, Kabupaten Aceh Tamiang.

\section{KESIMPULAN}

Berdasarkan hasil kegiatan pelatihan dan pendampingan bagi masyarakat petani ikan nila dapat disimpulkan bahwa masyarakat petani ikan nila Desa Paya Udang telah memahami betapa pentingnya manajemen kelompok dalam menjalankan usaha. Hal ini terlihat telah terbentuknya kelompok budidaya dengan nama "Pemuda Jaya" dengan jumlah anggota kelompok yaitu 8 orang yang diketuai oleh Ramzan. Kelompok budidaya ikan ini dikoordinir langsung dibawah BUMK Desa Paya Udang.

\section{UCAPAN TERIMA KASIH}

Penulis mengucapkan terima kasih kepada Direktorat Pembelajaran dan Kemahasiswaan, Kementerian Pendidikan, Kebudayaan, Riset dan Teknologi yang telah mendanai kegiatan pengabdian kepada masyarakat melalui skema kegiatan Program Holistik Pembinaan dan Pemberdayaan Desa (PHP2D) tahun 2021. Penulis juga mengucapkan terima kasih kepada Rektor Universitas Samudra, Pemerintah Kabupaten Aceh Tamiang, Pemerintah Desa Paya Udang, dosen dan mahasiswa Universitas Samudra, serta masyarakat Desa Paya Udang.

\section{DAFTAR PUSTAKA}

Alatas, U. H. (2018). Pelatihan budi daya ikan nila dalam rangka untuk meningkatkan kewirausahaan kelompok petani sawit (studi kasus pada kelompok petani di Sungai Kapas Kecamatan Bangko Kabupaten Merangin). Jurnal Pendidikan Unsika, 6(1), 81-88. https://journal.unsika.ac.id/index.php/judika/article/view/1229/1019.

Chakraborty, A., Mutingi, M., \& Vashishth, A. (2019). Quality management practices in SMEs: a comparative study between India and Namibia. Benchmarking, 26(5), 1499-1516. https://doi.org/10.1108/BIJ-08-2017-0210. 
Macias-Jimines, M. A., Acorta-Fontalavo, L. C., \& Jaminez-Barrons, M. A. (2019). Documentasi Menagement Practices in SMEs: ab information management Capability-based approach. Records Menagement Jornal. 30(1): 63-79.

Rahayu, M., \& Magdalena, B. (2021). Determinants Factors of Crafters Performance of SME's at Tapis, Province of Lampung. Widyakala: Journal of Pembangunan Jaya University, 8(1), 10. https://doi.org/10.36262/widyakala.v8i1.409.

Rudiono, D., Listianti, E., Astuti, I. Y., Jatmiko, U., \& Hibrida, A. R. (2021). Pelatihan Peningkatan Kapasitas Kelembagaan SPR "Ngudi Rukun" di Desa Gondang Kecamatan Plosoklaten, Kabupaten Kediri. Science Contribution to Society Journal, 1(1), 36-44. https://ejournal.unisbablitar.ac.id/index.php/scs/article/view/1716/1122.

Thassanabanjong, K., Miller, P., \& Marchant, T. (2015). Training Thai SMEs: Journal of Small Business and Enterprise Development. 16(4): 678-693.

Wahyuni, N. M., Sara, I. M., \& Raka, A. A. G. (2020). Praktik manajemen kelompok perajin di Banjar Pande Cempaga Bangli. Jurnal Widya Laksana, 9(2), 244-250. https://ejournal.undiksha.ac.id/index.php/JPKM/article/view/22998.

Wicaksono, G. (2020). Pelatihan Manajemen Usaha dan Pengelolaan Keuangan pada Kelompok Tani Kopi Desa Solor Kabupaten Bondowoso. Abdimas Mahakam Journal, 4(1), 78-83. http://dx.doi.org/ 10.24903/jam.v4i1.775. 


\section{Halaman Ini Dikosongkan}

